Research Article

\title{
Spectrophotometric Determination of Calcium with Dibromo-p-methylsulfonazo
}

\author{
Xiao-Dong Li $\mathbb{D}^{1}$ and Qing-Zhou Zhai $\mathbb{D}^{2}$ \\ ${ }^{1}$ Department of Basic Science, Jilin Jianzhu University, 5088 Xincheng Street, Changchun 130118, Jilin Province, China \\ ${ }^{2}$ Research Center for Nanotechnology, South Campus, Changchun University of Science and Technology, 7186 Weixing Road, \\ Changchun 130022, China \\ Correspondence should be addressed to Xiao-Dong Li; lxdjlju@163.com
}

Received 17 October 2019; Revised 18 February 2020; Accepted 17 March 2020; Published 13 April 2020

Academic Editor: Robert Zaleśny

Copyright (C) 2020 Xiao-Dong Li and Qing-Zhou Zhai. This is an open access article distributed under the Creative Commons Attribution License, which permits unrestricted use, distribution, and reproduction in any medium, provided the original work is properly cited.

\begin{abstract}
Calcium is a necessary trace element in the human body, and its low or high content in the human body is not appropriate. It is very meaningful to study the level of calcium in the human body and to determine calcium content in blood. As people take calcium through food, the determination of calcium content in certain tea and calcium supplements is of great significance. In this study, a new method for the determination of calcium was established using dibromo- $p$-methylsulfonazo as a chromogenic agent. In this article, the optimal conditions for the color reaction of $\mathrm{Ca}^{2+}$ with dibromo- $p$-methylsulfonazo were established. In a hydrochloric acid medium, $\mathrm{Ca}^{2+}$ and dibromo- $p$-methylsulfonazo form a blue complex. At 624 nm maximum absorption wavelength, the apparent molar absorptivity for the determination of calcium is $3.32 \times 10^{4} \mathrm{~L} \cdot \mathrm{mol}^{-1} \cdot \mathrm{cm}^{-1}$. Beer's law is applied for $0-0.60 \mu \mathrm{g} / \mathrm{mL}$. The method has already been used in the determination of calcium in blood serum, whole blood, tea leaf, and calcium fudge with satisfactory results.
\end{abstract}

\section{Introduction}

Calcium is a necessary trace element in human body. The calcium needed by human body per day is about 120 to $1400 \mathrm{mg}$. About $80 \%$ of this come from food and about $20 \%$ are provided by drinking water containing calcium. The lack of calcium element is bound to cause harm to human health. Calcium is not only the basic raw material for bone development and directly influences on stature but also has other important physiological functions in vivo [1]. These functions play an important role in maintaining the health of the body and ensuring the smooth development of normal growth. Calcium can promote the activities of some enzymes in the body, regulate the activity of enzymes, and participate in the activities of the nerves, muscles, and the release of neurotransmitters. Calcium is also important in regulation of the secretion of hormones, blood coagulation, cell adhesion, and muscle contraction. Calcium also has the functions to regulate heart rhythm, reduce cardiovascular permeability, control inflammation and edema, and maintain acid-base balance [2]. In daily life, if calcium intake is insufficient, the human body will suffer from physiological calcium overdraft, resulting in a decrease in blood calcium levels. Calcium deficiency leads to osteoporosis, hyperosteogeny, rickets in children, spasm of the hand and foot, hypertension, kidney stones, colon cancer, dementia, and other diseases. However, excessive calcium intake can also give rise to adverse effects, such as increasing the risk of kidney stones and affecting the absorption of other metals elements, such as iron and magnesium [3]. The determination of calcium in human blood is of great significance in the study of human health. The determination of calcium in tea leaves and calcium supplements such as calcium soft sugar is of great significance to study the effect of calcium on human health. Although some analytical methods such as inductively coupled plasma-atomic emission spectrometry [4], atomic absorption spectrometry [5-9], and ion chromatography [10] have been proposed, for these methods the 
price of the instruments is high or the operation is complicated. Spectrophotometry is characterized by simple operation and use of a cheap instrument and can be easily to be popularized and used. Dibromo- $p$-methylsulfonazo is cheap and easy to be synthesized. The optimum experimental conditions for the determination of calcium by spectrophotometry with dibromo-p-methylsulfonazo as chromogenic agent were established. The method has been successfully applied to the determination of calcium in serum, whole blood, tea leaves, and calcium fudge with satisfactory results.

\section{Experiment}

2.1. Instruments and Main Reagents. A Model 722S spectrophotometer (Shanghai Third Analytical Instrument Factory, China) equipped with $1 \mathrm{~cm}$ cells was used for the determination of absorbance.

$\mathrm{Ca}^{2+}$ standard solution: $0.2497 \mathrm{~g}$ of calcium carbonate were weighed, placed in a $100 \mathrm{~mL}$ beaker, $30 \mathrm{~mL}$ water were added, and $1 \mathrm{~mL}$ concentrated hydrochloric acid $(12 \mathrm{~mol} / \mathrm{L})$ was carefully added. The mixture was agitated to release carbon dioxide, diluted to $100 \mathrm{~mL}$ with water, and $1.000 \mathrm{mg}$ / $\mathrm{mL}$ calcium (II) reserve solution was obtained. The working solution was diluted by this stock solution. Dibromo- $p$ methylsulfonazo solution: $0.0050 \mathrm{~g}$ of dibromo- $p$-methylsulfonazo was dissolved in $100 \mathrm{~mL}$ water, and the solution where the content of the chromogenic agent was $0.050 \%$ (W/ V) was obtained. $4 \mathrm{~mol} / \mathrm{L}$ hydrochloric acid solution was used to adjust acidity.

2.2. Standard Procedure. In a $10 \mathrm{~mL}$ volumetric bottle, a certain amount of $\mathrm{Ca}^{2+}$ working solution (conditional experiment, $4.0 \mu \mathrm{g} \mathrm{Ca}^{2+}$ ) was added, and $2.5 \mathrm{~mL}$ of $0.050 \%$ (W/ V) dibromo- $p$-methylsulfonazo solution and $1.5 \mathrm{~mL}$ of $4 \mathrm{~mol} / \mathrm{L}$ hydrochloric acid were added. Water was added to the mark. It was allowed to stand for $30 \mathrm{~min}$. At the wavelength of $624 \mathrm{~nm}$, the absorbance of the chromogenic solution was determined with $1 \mathrm{~cm}$ cells by using the corresponding reagent blank as the reference.

\subsection{Sample Analysis}

2.3.1. Blood Sample. $0.5000 \mathrm{~g}$ serum or the whole blood sample was weighed, $3 \mathrm{~mL}$ concentrated nitric acid $(15.5 \mathrm{~mol} / \mathrm{L})$ and $1 \mathrm{~mL}$ concentrated hydrochloric acid $(12 \mathrm{~mol} / \mathrm{L})$ was added to digest for $5 \mathrm{~min}$, and evaporated to nearly dry. The residue was dissolved with $5 \mathrm{~mL}$ of $1 \%(\mathrm{~V} / \mathrm{V})$ hydrochloric acid solution and then transferred into a beaker. Water was used to dilute to the constant volume of $25 \mathrm{~mL}$. $2.0 \mathrm{~mL}$ of the solution was determined by the standard procedure.

2.3.2. Tea Leaves. $1.000 \mathrm{~g}$ of tea leaves were weighed, dried, finely polished, placed in a porcelain crucible, dried in the oven, and then heated by a small fire on an electric furnace, so that the sample was fully carbonized to smokeless. Then, it was put in a muffle furnace and heated to $600^{\circ} \mathrm{C}$ to be incinerated to white. After cooling, $20 \mathrm{~mL}$ of deionized water was added, heated and dissolved, then rocked, and rested. After the residue was filtered out, $20 \mathrm{~mL}$ of water was used to wash the residue for 3 times, then the filtrate was wholly transferred into a $100 \mathrm{~mL}$ volumetric flask, and water was added to the scale mark for further use. $2.0 \mathrm{~mL}$ of the solution was taken for determination according to the experimental method.

2.3.3. Calcium Fudge. $0.1000 \mathrm{~g}$ of the calcium fudge sample was weighed and placed in a beaker. A certain amount of water was added. $4 \mathrm{~mL}$ of aqua regia (hydrochloric acid: nitric acid $=3: 1, \mathrm{~V} / \mathrm{V}$ ) was dropwise added, heated to dissolve, and cooled. After transferring it to a $250 \mathrm{~mL}$ measuring flask, water was used to fill to the scale mark. $1.0 \mathrm{~mL}$ was taken and diluted to $25 \mathrm{~mL}$, and $2.0 \mathrm{~mL}$ of the solution was taken and determined by the experimental method.

\section{Results and Discussion}

3.1. Absorption Spectra. Figure 1 shows the absorption spectra of the reagent blank solution and the complex formed by $\mathrm{Ca}^{2+}$ and dibromo- $p$-methylsulfonazo. The maximum absorption wavelength of reagent blank against water is located at $530 \mathrm{~nm}$. The maximum absorption wavelength of the complex against blank reagent is located at $624 \mathrm{~nm}$, and the contrast $\triangle \lambda=94 \mathrm{~nm} .624 \mathrm{~nm}$ was chosen as the measuring wavelength in the experiment.

\subsection{Optimization of Experimental Conditions}

3.2.1. Color Acidity. According to the experimental method, the effect of different acidity on the color reaction was investigated. When the dosage of $4 \mathrm{~mol} / \mathrm{L}$ hydrochloric acid was $0-1.2 \mathrm{~mL}$, the absorbance gradually increased with the increase of hydrochloric acid dosage. When the dosage of hydrochloric acid was $1.2 \sim 1.8 \mathrm{~mL}$, the absorbance was larger and the fluctuation was small. The absorbance decreased when the amount of hydrochloric acid was larger than $1.8 \mathrm{~mL}$. In the experiment, adding $1.5 \mathrm{~mL}$ of $4 \mathrm{moL} / \mathrm{L}$ hydrochloric acid was selected. At this time, the acidity of the medium was $0.6 \mathrm{~mol} / \mathrm{L}$.

3.2.2. Amount of Dibromo-p-methylsulfonazo. The experiment shows that the absorbance increased gradually with the increase in amount of dibromo-p-methylsulfonazo in a certain concentration range. When the dosage of dibromop-methylsulfonazo was $2.2-2.6 \mathrm{~mL}$, the absorbance was larger and the fluctuation was small. In the experiment, $2.5 \mathrm{~mL}$ of $0.050 \%$ (W/V) dibromo- $p$-methylsulfonazo solution was selected to be added. At this time, the concentration of the dibromo- $p$-methylsulfonazo was $7.3 \times$ $10^{-4} \mathrm{~mol} / \mathrm{L}$.

3.2.3. Effect of Surfactant. According to the experimental method, the effect of surfactants was observed. A certain amount of surfactants of different properties was, 


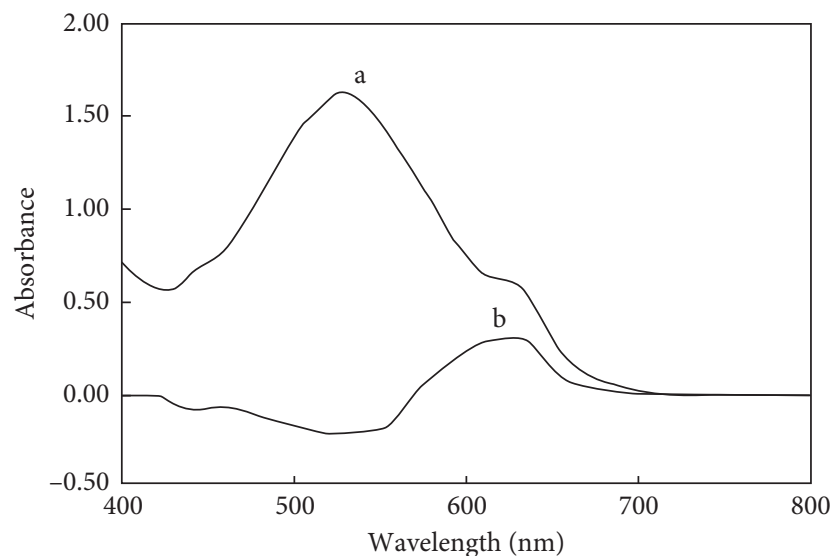

FIGURE 1: Absorption spectra. (a) Reagent blank (against water); (b) complex (against reagent blank); $\left(\mathrm{Ca}^{2+}\right)=1.0 \times 10^{-5} \mathrm{~mol} / \mathrm{L},(\mathrm{dibromo}-\mathrm{p}-$ methylsulfonazo $)=7.3 \times 10^{-4} \mathrm{~mol} / \mathrm{L},[\mathrm{HCl}]=0.60 \mathrm{~mol} / \mathrm{L}$.

TABLE 1: Analytical results of samples.

\begin{tabular}{|c|c|c|c|c|c|c|c|}
\hline Sample & Found $(n=11, \mu \mathrm{g} / \mathrm{g})$ & $\begin{array}{c}\text { Average } \\
(\mu \mathrm{g} / \mathrm{g})\end{array}$ & $\begin{array}{l}\text { Relative } \\
\text { standard } \\
\text { deviation } \\
\quad(\%)\end{array}$ & $\begin{array}{l}\text { Added } \\
(\mu \mathrm{g} / \mathrm{mL})\end{array}$ & $\begin{array}{c}\text { Recovered } \\
(\mu \mathrm{g} / \mathrm{mL})\end{array}$ & $\begin{array}{c}\text { Recovery } \\
(\%)\end{array}$ & $\begin{array}{l}\text { Atomic absorption } \\
\text { spectrometric } \\
\text { method }(\mu \mathrm{g} / \mathrm{g})\end{array}$ \\
\hline Serum & $\begin{array}{c}76.52,72.46,78.25,71.87,74.25,74.58 \\
75.68,75.89,73.21,72.89,76.43\end{array}$ & 74.38 & 2.49 & 0.200 & 0.206 & 103.34 & 74.51 \\
\hline Whole blood & $\begin{array}{c}102.46,104.76,111.49,112.38,108.47 \\
108.72,109.91,106.73,108.62,114.55 \\
106.98\end{array}$ & 108.35 & 1.49 & 0.200 & 0.191 & 95.41 & 108.11 \\
\hline Tea & $\begin{array}{c}25.48,19.56,20.28,19.49,24.77,26.36 \\
23.52,23.84,26.39,21.18,22.33\end{array}$ & 23.74 & 1.26 & 0.200 & 0.195 & 97.46 & 23.74 \\
\hline $\begin{array}{l}\text { Calcium } \\
\text { fudge }(\%)\end{array}$ & $\begin{array}{c}6.25,6.33,6.17,6.25,6.17,6.17,6.33 \\
6.33,6.39,6.11,6.25\end{array}$ & 6.25 & 1.41 & 0.200 & 0.193 & 96.27 & 176.44 \\
\hline
\end{tabular}

respectively, added: cationic surfactant cetyltrimethylammonium bromide, anionic surfactant sodium dodecyl sulfonate, and nonionic surfactant Tween-80, OP-100. The results showed that the sensitivity of calcium determination was decreased by adding four kinds of surfactants. The reason is that, in such a high acidic medium, the surfactants combined with $\mathrm{H}^{+}$and the surfactants could not take action with the complex formed between calcium and the chromogenic agent.

3.3. Stability and Composition of Complex. The experimental results showed that when $0.40 \mu \mathrm{g} / \mathrm{mL} \mathrm{Ca}^{2+}$ were determined, dibromo- $p$-methylsulfonazo and $\mathrm{Ca}^{2+}$ produced a complex in $15 \mathrm{~min}$, the complex remained stable within $65 \mathrm{~min}$ at least, and the absorbance change was less than $5 \%$.

The composition ratio of the $\mathrm{Ca}$ (II)-dibromo-p-methylsulfonazo complex was determined to be $2: 1$ by the molar ratio method and equimolar continuous change method.

3.4. Working Curve. Under optimal conditions, linear range experiment was carried out. The results showed that over the range of $0-0.60 \mu \mathrm{g} / \mathrm{mL}$ of $\mathrm{Ca}^{2+}$ Beer's law is obeyed. Its linear regression equation is $A=0.827 \mathrm{C}(\mu \mathrm{g} / \mathrm{mL})+0.0004$, with a correlation coefficient $r=0.9991$. The apparent molar absorptivity for the determination of calcium by the method was $3.32 \times 10^{4} \mathrm{~L} \cdot \mathrm{mol}^{-1} \cdot \mathrm{cm}^{-1}$. Eleven times parallel determination for $0.40 \mu \mathrm{g} / \mathrm{mL} \mathrm{Ca}^{2+}$ working solution and blank reagent were carried out, the relative standard deviation of the method calculated was $0.99 \%$, and the detection limit (DL) of the method obtained was $\mathrm{DL}=3 S / K=9.33 \mathrm{ng} / \mathrm{mL}$ ( $S$ : the standard deviation of eleven parallel determination, $K$ : the slope of regression equation).

3.5. Effect of the Coexisting Substance. Under the optimal experimental conditions, the experiment of influence of coexisting substances was carried out. For the determination of $0.40 \mu \mathrm{g} / \mathrm{mL} \mathrm{Ca}^{2+}$, when the relative error does not exceed $\pm 5 \%$, the allowable amount (mass multiple) of each coexisting substance is as follows: $\mathrm{Mn}^{2+}, \mathrm{F}^{-}, \mathrm{SO}_{4}^{2-}, \mathrm{CO}_{3}^{2-}, \mathrm{PO}_{4}^{3-}(800)$; $\mathrm{Fe}^{3+}\left(400,1000^{*}\right), \mathrm{Fe}^{2+}(200) ; \mathrm{Ni}^{2+}(100) ; \mathrm{Li}^{+}, \mathrm{Br}^{-}, \mathrm{Cu}^{2+}, \mathrm{Co}^{2+}$, $\mathrm{NO}_{2}{ }^{-}, \mathrm{VO}_{3}{ }^{-}(50) ; \mathrm{Ba}^{2+}, \mathrm{Pb}^{2+}, \mathrm{Zn}^{2+}$ (40); $\mathrm{Mg}^{2+}$ (40, 100*); $\mathrm{NO}_{3}^{-}(30) ; \mathrm{Ag}^{+}, \mathrm{I}^{-}, \mathrm{S}_{2} \mathrm{O}_{7}^{2-}, \mathrm{Mo}_{7} \mathrm{O}_{24}^{6-}(20) ; \mathrm{Al}^{3+}\left(20,50^{*}\right)$, $\mathrm{BrO}_{3}{ }^{-}, \mathrm{SiO}_{3}^{2-}(10) ; \mathrm{MnO}_{4}^{-}(5)$; and $\mathrm{Bi}^{3+}, \mathrm{Cr}^{3+}$, and $\mathrm{Cr}(\mathrm{VI})$ (1). Phenylalanine, bovine serum albumin, cysteine, glutamic acid, lysine, alginine, citric acid, salicylic acid (50), glucose, ascorbic acid (20), and bovine hemoglobin (5) (illustration:* adding $2 \mathrm{~mL}$ of $0.5 \mathrm{mg} / \mathrm{mL}$ EDTA(ethylenediaminetetraacetate)$\mathrm{Na}_{2}$ to mask $\mathrm{Fe}^{3+}, \mathrm{Al}^{3+}, \mathrm{Mg}^{2+}$ ).

3.6. Results of Sample Analysis. In this paper, blood sample, tea sample, and calcium fudge samples were determined. For 
the above mentioned samples, standard-added recovery experiments were simultaneously performed, and the recovery rate of the determination method and the analytical results are shown in Table 1. For the tests of above mentioned samples, the standard addition recovery experiments were carried out at the same time to determine the recovery rate of the method. The analytical results are shown in Table 1 . The recovery rates of determination sample by the method were $95.41 \%-103.34 \%$, and the average recovery rate was $98.12 \%$. The relative standard deviation of eleven determinations was $0.90 \%-2.49 \%$, and the average relative standard deviation was $1.66 \%$. The results determined by this method are in agreement with those by atomic absorption spectrometry. Determination of calcium by the present method has the advantages of high accuracy and good precision.

\section{Conclusions}

In this article, by using dibromo-p-methylsulfonazo as chromogenic agent, the optimum experimental conditions for the determination of calcium by spectrophotometry were established. The apparent molar absorptivity of calcium determined by the method at the maximum absorption wavelength $624 \mathrm{~nm}$ is $3.32 \times 10^{4} \mathrm{~L} \cdot \mathrm{cm}^{-1} \cdot \mathrm{mol}^{-1}$, in the range of $0-0.60 \mu \mathrm{g} / \mathrm{mL}$ of $\mathrm{Ca}^{2+}$ Beer's law is obeyed, and the linear regression equation for the determination of calcium is $A=0.827 \mathrm{C}(\mu \mathrm{g} / \mathrm{mL})+0.0004$, with a correlation coefficient of 0.9991 . The present method has been successfully applied to the determination of calcium in serum, whole blood, tea leaf, and calcium fudge with satisfactory results. The recovery rate of the actual samples determined by this method was $95.14 \%-103.34 \%$, and the results are consistent with the atomic absorption spectrometry method.

\section{Data Availability}

The data used to support the findings of this study are included within the article.

\section{Conflicts of Interest}

The authors declare that they have no conflicts of interest.

\section{Acknowledgments}

This work was supported by the Science Research Project of Education Department, Jilin Province, from the 13th FiveYear Plan, China (JJKH20200265KJ).

\section{References}

[1] A. M. Gao, "Essential nutrients for the human body-calcium," Microelement Health Research, vol. 22, no. 2, pp. 66-67, 2005.

[2] X. M. Li, H. X. Huang, and J. B. Hu, "Calcium and human body and clinic," Guangdong Microelement Science, vol. 10, no. 2, pp. 67-69, 2003.

[3] S. Z. Li, Essential Elements and Health, Light Industry Press, Beijing, China, 1998.

[4] Q. Zhao, H. Wang, and H. Li, "ICP-AES method for simultaneous determination of 11 impurity elements in high purity lithium carbonate," Journal of Southwest University for Nationalities (Natural Science Edition), vol. 29, no. 5, pp. 541-543, 2003.

[5] X. Q. Chen, F. H. Li, and C. Y. Fang, "Determination of micro amount calcium by atomic absorption spectrometry with OP as sensitizer," Physical Testing and Chemical Analysis (Part B), vol. 37, no. 6, pp. 275-277, 2001.

[6] J. L. Li and S. Z. Wang, "Determination of the calcium content in health foods by flame atomic absorption spectrometry," Occupation and Health, vol. 29, no. 17, pp. 2165-2166, 2013.

[7] X. W. Luo, "Determination of calcium in feed by flame atomic absorption spectrometry," Chinese Journal of Spectroscopy Laboratory, vol. 21, no. 3, pp. 333-335, 2004.

[8] F. Y. Wang, "Atomic absorption spectrophotometric determination of calcium in calcium carbonate tablets," Chinese Journal of Health Laboratory Technology, vol. 17, no. 11, pp. 66-67, 2007.

[9] L. Y. Zheng, Y. J. Zhu, Y. Gao, and Y. Wang, "Research progress on the determination of calcium in feed," Animals Breeding and Feed, vol. 20, no. 2, pp. 23-26, 2009.

[10] J. C. Dai, X. G. Teng, and P. H. Ma, "Determination of micro amount potassium, calcium, sodium, magnesium and ammonium ion in high purity lithium fluoride by ion chromatography," Chinese Journal of Chromatography, vol. 21, no. 6 , p. $629,2003$. 